\title{
Recurrent pyoderma in a family with a defect in leucocyte locomotion
}

\author{
C C ZIELINSKI， P A DREMSEK， R AHMAD， M M EIBL
}

\begin{abstract}
Granulocyte functions including leucocyte locomotion and chemoluminescence were studied in three generations of a family in which all male members had presented with recurrent pyoderma. While parameters of humoral immunity including serum concentrations of IgG, IgA, IgM, and IgE and of complement components $\mathrm{C3}$ and $\mathrm{C4}$ as well as the response of mononuclear leucocytes to mitogens proved to be within the normal range, leucocyte locomotion was found to be severely impaired in all affected subjects. Moreover, granulocyte dysfunction in male members was associated with the occurrence of a single haplotype (HLA-A2, B13, DR7).

These findings suggest that the defect in leucocyte locomotion and the pyoderma might not only have been inherited in an $X$ linked manner but might also have been linked to a gene within the inherited HLA haplotype.
\end{abstract}

\section{Introduction}

Defects of granulocyte function such as impaired locomotion present clinically with increased susceptibility to infections, usually of soft tissue, by micro-organisms of low virulence. Defects of leucocyte function may occur sporadically within a population, ${ }^{1-3}$ but several distinct disease entities associated with impaired leucocyte locomotion are inherited. These include such disparate disorders as the lazy leucocyte syndrome, ${ }^{4}$ Chédiak-Higashi syndrome, ${ }^{5}$ and Job's ${ }^{6}$ or the hyperimmuno-

II Department of Medicine, Vienna University Hospital; Gottfried von Preyer Children's Hospital; and the Institute of Immunology, University of Vienna, Austria

C C ZIELINSKI, MD

P A DREMSEK, MD

R AHMAD, DVM

M M EIBL, MD, professor of immunology

Correspondence to: Dr Christoph C Zielinski, II Department of Medicine, Vienna University Hospital, A-1090 Vienna, Austria. globulinaemia $\mathrm{E}^{\text {? }}$ syndrome. In some of these entities the mode of inheritance of defective leucocyte locomotion is unknown.

We describe three generations of a family in which all male members were affected by recurrent pyoderma. While chemoluminescence of the patients' granulocytes was unimpaired, leucocyte locomotion proved to be defective. The clinical and laboratory data were not typical of any of the syndromes recognised as associated with this abnormality.

\section{Subjects and methods}

Three boys aged 2 (subject 8 ), 3 (subject 10), and 8 years (subject 9) (see figure) presented with severe recurrent pyoderma. Two were brothers (subjects 9 and 10) and the other their first degree cousin (figure). All had been delivered after normal, uncomplicated pregnancies, and their parents were not related by blood. Their previous histories contained nothing of note. The family history disclosed pyoderma of varying degree in all male members, including the children's fathers (subjects 5 and 6 ) and grandfather (subject 1). The grandmothers (subjects 2 and 3 ) and mothers (subjects 4 and 7) were free of symptoms. No member of the family had diabetes or any other metabolic disorder.

Physical examination of the children disclosed multiple abscesses concentrated mainly on legs and buttocks, thoracic region, and face. The area surrounding the abscesses showed no appreciable inflammatory changes. At the children's first presentation one or more abscesses were incised, and in all cases coagulase positive Staphylococcus aureus was cultured. No other clinical abnormalities were noted.

Leucocyte locomotion assays were performed by a modification of Boyden's Micropore filter technique. ${ }^{8-10}$ Briefly, leucocytes were obtained by sedimentation of whole heparinised (50 IU preservative free heparin $/ \mathrm{ml}$ ) blood with $2 \%$ dextran 500 (Pharmacia, Uppsala, Sweden). After repeated washings the leucocytes were suspended in RPMI 1640 (Gibco, Grand Island, New York) supplemented with $100 \mathrm{IU}$ penicillin and $100 \mu \mathrm{g}$ streptomycin $(\mathrm{Gibco}) / \mathrm{ml}$. The number of cells was adjusted to $2.5 \times 10^{6} / \mathrm{ml}$. A $0.5 \mathrm{ml}$ sample of the cell suspension was pipetted into the upper compartment of a chemotaxis chamber, while the lower compartment contained $1.5 \mathrm{ml}$ of either $0.1 \%$ casein (Merck, West Germany) diluted in phosphate buffered saline or phosphate buffered saline only. The two compartments were separated by a Micropore filter with $3 \mu \mathrm{m}$ pore size (Millipore Corp, Bedford, MA). After incubation for 120 minutes at $37^{\circ} \mathrm{C}$ in $5 \%$ carbon dioxide the filters were detached, mounted on slides, stained with haemalum, and cleared in xylene. All assays were 
performed in triplicate. The number of cells that had migrated through the filter to the lower surface was evaluated in 10 high power oil immersion fields and the resulting number of cells in triplicate filters expressed as mean and standard deviation (SD); this was the locomotion index. Five healthy controls matched for sex and age were tested in parallel with the patients, and data on eight further controls tested during the same period were included for additional analysis of the results.

Assay for chemoluminescence of leucocytes was performed by the method of Grebner et al. ${ }^{11}$ Briefly, leucocytes were induced to phagocytose zymosan particles (Sigma Chemical Co, St Louis, MO).

TABLE I-Results of leucocyte locomotion assays

\begin{tabular}{cccc}
\hline $\begin{array}{c}\text { Subject } \\
\text { No }\end{array}$ & Sex & $\begin{array}{c}\text { Mean locomotion index } \\
(\text { SD })\end{array}$ & $\begin{array}{c}\text { State of leucocyte locomotion } \\
\text { (compared with controls*) }\end{array}$ \\
\hline 1 & $\mathrm{M}$ & $1 \cdot 4(1 \cdot 0)$ & Impaired \\
2 & $\mathrm{~F}$ & $2 \cdot 7(0 \cdot 6)$ & Impaired \\
3 & $\mathrm{~F}$ & $7 \cdot 1(0 \cdot 2)$ & Iormal \\
4 & $\mathrm{~F}$ & $3 \cdot 3(0 \cdot 5)$ & Impaired \\
5 & $\mathrm{M}$ & $2 \cdot 7(0 \cdot 7)$ & Impaired \\
6 & $\mathrm{M}$ & $3 \cdot 9(0 \cdot 3)$ & Impaired \\
7 & $\mathrm{~F}$ & $4 \cdot 8(2 \cdot 2)$ & Impaired \\
8 & $\mathrm{M}$ & $4 \cdot 0(0 \cdot 3)$ & ND \\
9 & $\mathrm{M}$ & $\mathrm{ND}$ & Impaired \\
10 & $\mathrm{M}$ & $1 \cdot 7(0 \cdot 9)$ &
\end{tabular}

$\mathrm{ND}=$ Not done

*Five healthy controls investigated in parallel with patients, and eight additiona controls analysed during same time period were added. Locomotion index for all controls $7 \cdot 14$ (SD $1 \cdot 15)$

Impairment postulated for $\mathrm{p}<0.001$ in $t$ tests for both paired samples and independent data. different concentrations, pokeweed mitogen in two dilutions (both mitogens purchased from Gibco), and concanavalin A (Pharmacia) according to standard methods.

$H L A$ typing was carried out on peripheral blood cells at the Institute of Serology, University of Vienna.

Statistics-Results are expressed as means and SD. Statistical analyses were performed by Student's $t$ test for independent data and for paired samples.

\section{Results}

\section{GRANULOCYTE FUNCTION ASSAYS}

Leucocyte locomotion assayed with $0.1 \%$ casein diluted in phosphate buffered saline used as chemotaxigen was significantly reduced (table I) in all male members of the family tested when compared with the locomotion of leucocytes from healthy controls tested in parallel $(p<0.001)$. Values remained significantly reduced when compared with those of the eight additional healthy controls tested in the same time period (locomotion index for all controls $7 \cdot 14$ (SD 1.15); $\mathrm{p}<0.001$ ). Random mobility of patients' leucocytes with phosphate buffered saline in the lower compartment of the chemotaxis chamber was not defective as compared with leucocytes of healthy controls $(p>0 \cdot 1)$. Interestingly, the children's mothers and one grandmother showed a decrease in leucocyte locomotion, although they were free of symptoms (table I).

Assays for chemoluminescence were performed in all family members but one (subject 9), and all produced results comparable to those of the healthy controls who were tested in parallel.

TABLE II-Data obtained in assays of immune function

\begin{tabular}{|c|c|c|c|c|c|c|c|c|c|c|}
\hline \multirow{2}{*}{$\begin{array}{l}\text { Subject } \\
\text { No }\end{array}$} & \multicolumn{4}{|c|}{$\begin{array}{l}\text { Concentrations of } \\
\text { immunoglobulins }\end{array}$} & \multicolumn{2}{|c|}{$\begin{array}{l}\text { Concentrations of } \\
\text { complement }\end{array}$} & \multirow{2}{*}{$T$ T cells } & \multicolumn{3}{|c|}{ Stimulation with mitogens (counts $/ \min \times 10^{3}$ ) } \\
\hline & $\begin{array}{l}\mathrm{IgG} \\
(\mathbf{g} / \mathrm{l})\end{array}$ & $\underset{(\mathbf{g} / \mathbf{l})}{\mathbf{I g A}}$ & $\underset{(\mathrm{g} / \mathrm{l})}{\mathrm{IgM}}$ & $\begin{array}{l}\text { IgE } \\
\text { (IU) }\end{array}$ & $\begin{array}{l}\mathrm{C3} \\
(\mathrm{g} / \mathrm{l})\end{array}$ & $\begin{array}{c}\mathrm{C} 4 \\
(\mathrm{~g} / \mathrm{l})\end{array}$ & & Phytohaemagglutinin & $\begin{array}{c}\text { Pokeweed } \\
\text { mitogen }\end{array}$ & Concanavalin A \\
\hline $\begin{array}{r}1 \\
2 \\
3 \\
4 \\
5 \\
6 \\
7 \\
8 \\
9 \\
10\end{array}$ & $\begin{array}{r}26.49 \\
12.33 \\
7.50 \\
11.72 \\
15.72 \\
16.60 \\
12.63 \\
5.33 \\
10.33 \\
9.78\end{array}$ & $\begin{array}{l}9.16 \\
1.40 \\
3.16 \\
2.16 \\
3.33 \\
2.89 \\
0.87 \\
0.78 \\
1.16 \\
0.51\end{array}$ & $\begin{array}{l}3.94 \\
1.97 \\
1.75 \\
2.52 \\
1.98 \\
1.56 \\
1.56 \\
2.49 \\
1.59 \\
1.01\end{array}$ & $\begin{array}{r}145 \\
3 \\
19 \\
30 \\
110 \\
135 \\
<1 \\
22 \\
130 \\
30\end{array}$ & $\begin{array}{l}1.51 \\
1.12 \\
1.52 \\
1.57 \\
1.42 \\
1.20 \\
1.25 \\
2.47 \\
1.90 \\
1.89\end{array}$ & $\begin{array}{l}0.47 \\
0.22 \\
0.41 \\
0.36 \\
0.36 \\
0.36 \\
0.18 \\
0.60 \\
0.36 \\
0.41\end{array}$ & $\begin{array}{l}70 \\
\text { ND } \\
64 \\
\text { ND } \\
42 \\
71 \\
68 \\
54 \\
74 \\
\text { ND }\end{array}$ & $\begin{array}{r}44 \\
\text { ND } \\
51 \\
\text { ND } \\
55 \\
59 \\
86 \\
83 \\
100 \\
\text { ND }\end{array}$ & $\begin{array}{l}28 \\
\text { ND } \\
13 \\
\text { ND } \\
7 \\
8 \\
25 \\
28 \\
6 \\
\text { ND }\end{array}$ & $\begin{array}{l}15 \\
\text { ND } \\
14 \\
\text { ND } \\
22 \\
10 \\
47 \\
\text { ND } \\
20 \\
\text { ND }\end{array}$ \\
\hline
\end{tabular}

$\mathrm{ND}=$ Not done

TABLE III-Results of HLA typing

\begin{tabular}{|c|c|c|c|c|}
\hline Subject No & A & B & $\mathrm{C}$ & DR \\
\hline $\begin{array}{l}1 \\
2\end{array}$ & $\begin{array}{l}2,26 \\
\text { ND }\end{array}$ & 12,13 & w2 & 2,7 \\
\hline $\begin{array}{r}3 \\
4 \\
5 \\
6 \\
7 \\
8 \\
9 \\
10\end{array}$ & $\begin{array}{l}1,2 \\
1,11 \\
2 \\
2, \text { w24 } \\
1,2 \\
1,2 \\
1,2\end{array}$ & $\begin{array}{c}8,15 \\
27,40 \\
13,15 \\
12,13 \\
8, w 38 \\
13,27 \\
13, \text { w38 } \\
8,13\end{array}$ & $\begin{array}{l}\text { w4 } \\
\text { w1, } 13 \\
\text { w4 } \\
= \\
\overline{w 4} \\
=\end{array}$ & $\begin{array}{l}1,3 \\
1,7 \\
1,7 \\
5,7 \\
3 \\
1,7 \\
7 \\
3,7\end{array}$ \\
\hline
\end{tabular}

$\mathrm{ND}=$ Not done

The light emission achieved in the presence of luminol (Lumac, The Netherlands) was measured immediately in a scintillation counter (Biocounter M 2010; Lumac) and the results of chemoluminescence intensity plotted as counts per minute versus time corrected to $10^{5}$ leucocytes. In all experiments the patients' leucocytes were assayed in parallel with the cells of at least one healthy control subject.

Serum immunoglobulin and complement concentrations were measured by a radial immunodiffusion technique (Diffu-Gen Radial Immunodiffusion Plates; Oxford Labs Inc, Foster City, CA). Haemolytic complement activity was measured by the method of Mayer. ${ }^{12}$

Stimulation of mononuclear cells with mitogens-Lymphocytes were separated from whole heparinised blood by a modification of the Ficoll-Hypaque (Pharmacia) buoyant density gradient method.13 Stimulations were performed with phytohaemagglutinin in three

\section{HUMORAL AND CELLULAR IMMUNITY}

Serum concentrations of $\operatorname{IgG}, \operatorname{IgA}, \operatorname{IgM}$, and $\operatorname{IgE}$ as well as of complement components $\mathrm{C} 3$ and $\mathrm{C} 4$ and haemolytic complement were within the normal range in all subjects tested (table II). Similarly, the patients' lymphocytes could be stimulated with a series of mitogens to a similar degree to that of lymphocytes from controls (table II).

\section{EXPRESSION OF HLA ANTIGENS}

Table III lists the HLA types found in the various family members. Defective leucocyte locomotion or the presence of symptoms, or both, occurred in association with the expression of a single HLA haplotype (HLA-A2. B13, DR7) (figure).

\section{Discussion}

The patients described here presented with recurrent pyoderma associated with a defect in leucocyte locomotion. Closer investigation disclosed that the children's fathers (who were brothers) as well as their grandfather had suffered from the same disorder, also associated with defective leucocyte locomotion. The defect in leucocyte locomotion, however, did not correspond obviously with any defect of leucocyte locomotion known to date. Thus leucocytes did not show any deviation in 


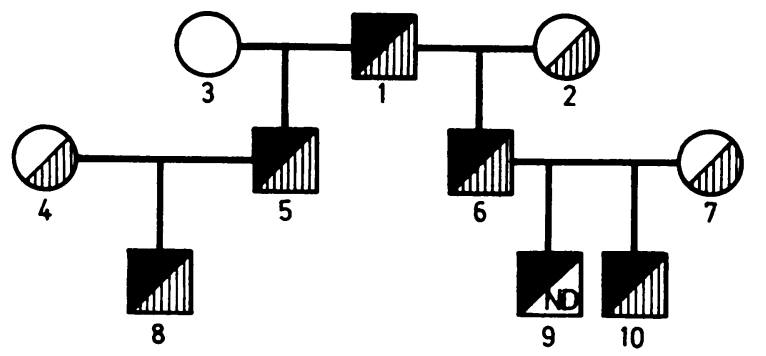

HLA haplotype : A2, B13, DR7

Impairment of leucocyte bcomotion

Family tree of subjects studied. All male members studied showed impaired leucocyte locomotion. Inheritance of single HLA haplotype indicated. (ND $=$ Not done.)

either number or morphology, and neither hypergammaglobulinaemia nor hypogammaglobulinaemia ${ }^{14-16}$ was present, suggesting that the defective locomotion was the only abnormality in a large range of immunological tests indicative of host defence. The defect of leucocyte locomotion and pyoderma were present in all male members of the family, while the women were free of symptoms. Chemoluminescence after ingestion of zymosan particles by leucocytes was normal in all members tested, so that an impairment of phagocytic and oxidative mechanisms appeared unlikely. ${ }^{11}$ The defect of leucocyte locomotion observed in the patients' mothers might have occurred as a secondary phenomenon due to repeated exposure to staphylococci present in their environment. ${ }^{17}$

Interestingly, all male members of the family had the same HLA haplotype. Hence the defect in leucocyte locomotion and the occurrence of symptoms might not only have been inherited in an $\mathrm{X}$ linked manner but might also have been linked to a gene within the inherited HLA haplotype. Further investiga- tions including more families with defects of leucocyte locomotion will be required to prove this and may shed new light on disturbances of leucocyte locomotion.

We are grateful to Dr W Mayr, Institute of Serology, University of Vienna, for HLA typing and to Drs H Ebner and D Kraft for measuring IgE concentrations.

\section{References}

1 Miller ME. Pathology of chemotaxis and random mobility. Semin Hematol 2 Quie PG, Cates RL. Clinical manifestations of disorders of neutrophil chemoQuie PG, Cates RL. Clinical manifestations of disorders of neutrophil chemo-
taxis. In: Gallin JI, Quie PG, eds. Leukocyte chemotaxis. New York: Raven

3 Clark RA. Disorders of granulocyte chemotaxis. In: Gallin JI, Quie PG, eds. Leukocyte chemotaxis. New York: Raven Press, 1978:329-56.

4 Miller ME, Oski FA, Harris MB. Lazy-leukocyte syndrome: a new disorder of neutrophil function. Lancet 1971 ; i :665-9.

Clark RA, Kimball HR. Defective granulocyte chemotaxis in the ChediakHigashi syndrome. F Clin Ivest $1971 ; 50: 2645-52$.
6 Hill HR, Ochs HD, Quie PG, Pabst HF, Klebanoff SJ, Wedgwood RJ. Defect in neutrophil granulocyte chemotaxis in Job's syndrome of recurrent "cold" staphylococcal abscesses. Lancet $1974 ;$ ii:617-9.

7 Hill HR, Quie PG. Raised serum IgE levels and defective neutrophil chemotaxis in three children with eczema and recurrent bacterial infections. Lancet $1974 ; \mathrm{i}: 183-7$.

8 Boyden S. The chemotactic effect of mixtures of antibody and antigen on polymorphonuclear leukocytes. F Exp Med 1962;115:453-66.

Frei PC, Baisero MH, Ochsner M. Chemotaxis of polymorphonuclears in vitro. f Immunol Methods 1974;6:357-86.

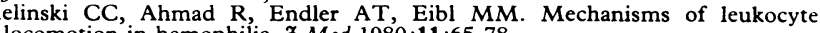

11 Grebner JV, Mills EL, Gray BH, Quie PG. Comparison of phagocytic and chemoluminescence response

2 Mayer MM. Experimental immunochemistry. 2nd ed. Springfield: CC Thomas, 1961:133-240.

3 Böyum A. Isolation of mononuclear cells and granulocytes from human blood: isolation of mononuclear cells by one centrifugation and of granulocytes by combining centrifugation and sedimentation at $1 \mathrm{~g}$. Scand $\mathcal{f}$ Clin Lab Invest 1968;21(suppl 97):77-89.

14 Steerman RL, Snyderman R, Leiken SL, Colten HR. Intrinsic defect of the polymorphonuclear leukocyte resulting in impaired chemotaxis and phagocytosis. Clin Exp Immunol 1971;9:939-46.

JA, Dayton DH, eds. The phagecytic and humoral components. In: Bellant JA, Dayton DH, eds.

16 Higgins GR, Swanson V, Yamazaki J. Granulocytasthenia. A unique leukocyte dysfunction associated with decreased resistance to infection. Clin Res 1970; 18:209.

17 Mowat AG, Baum J. Polymorphonuclear leukocyte chemotaxis in patients with bacterial infections. Br Med $\mathcal{F} 1971$; iii :617-9.

(Accepted 24 September 1984)

\title{
Efficacy of facemask resuscitation at birth
}

\author{
A D MILNER, H VYAS, I E HOPKIN
}

\section{Abstract}

The efficacy of facemask resuscitation was assessed by measuring the expiratory tidal volume during the first three inflations in nine babies with birth asphyxia and comparing the results with those obtained in a further nine babies resuscitated after endotracheal intubation. The facemask system was relatively inefficient, with tidal exchange less than one third of that seen after intubation and rarely sufficient to produce adequate alveolar ventilation. Successful resuscitation depended on stimulating the baby to make his own respiratory efforts.

Department of Child Health, City Hospital, Nottingham NG7 2UH A D MILNER, MD, FRCP, professor of paediatric respiratory medicine, department of neonatology

$\mathrm{H}$ VYAS, MB, MRCP, research fellow

I E HOPKIN, RSCN, research sister

Correspondence to: Professor A D Milner.

\section{Introduction}

Facemask resuscitation has been used for many years in the management of asphyxia at birth. It is easier and less invasive than intubation and so is often the first line of intervention by midwives. Although there have been no documented studies, it is generally accepted that most babies respond rapidly to facemask resuscitation and that it is a safe procedure. ${ }^{1}$ There have been worries that the positive pressure in the pharynx might lead to air passing down the oesophagus, producing gastric distension. This would tend to split the diaphragm and might impede tidal exchange. We, however, were unable to find any evidence that this occurred to any extent during standard facemask resuscitation in a recent study in which we measured both the facemask and oesophageal pressures during the procedure. ${ }^{2}$ As there have been no previous reports on the in vivo performance of these devices during resuscitation we considered it important to measure, in addition, both the inflation pressure and the resultant tidal exchange to assess whether these devices can maintain adequate ventilation during the first few minutes of life. We compared the results with 